\title{
Dental Implants as a Treatment Modality: Awareness Survey among People of Ahmedabad
}

${ }^{1}$ Rupal J Shah, ${ }^{2}$ Anandmayee Chaturvedi, ${ }^{3}$ Hemal Agarwal

\begin{abstract}
Aim: To assess the sources, level of awareness, and need for information about dental implants among patients attending the outpatient ward of department of Prosthodontics, Government Dental College and Hospital, Ahmedabad, India.
\end{abstract}

Materials and methods: A survey was conducted on 300 patients attending the outpatient ward department of prosthodontics, Government dental college and hospital, Ahmedabad. A printed questionnaire was used to evaluate the awareness about dental implants.

Result: Out of 300 patients only $41.33 \%$ had heard about the implant as treatment modality and most of them were of 16 to 30 age group (53.33\%). For most of the participants, dentist was the main sources of information about dental implants $(69.35 \%)$, and most of them were found to have interest to know about implants. $45.33 \%$ were willing to go under the treatment if needed, while $52.67 \%$ cited high costs as the main reason for refusal of the treatment if needed.

Conclusion: Patient should be informed about implants by conducting and implementing various public awareness campaigns, counseling centers should be established in patient outpatient ward in Prosthodontic departments of dental colleges and in private dental clinics. It also concludes that various efforts should be made by the public sector to lower the cost of implants so that they can be made affordable to all who are in need and to improve their oral health.

Keywords: Awareness, Implants, Implant awareness, Ahmedabad.

How to cite this article: Shah RJ, Chaturvedi A, Agarwal $\mathrm{H}$. Dental Implants as a Treatment Modality: Awareness Survey among People of Ahmedabad. Int J Prosthodont Restor Dent 2014;4(2):35-38.

\section{Source of support: Nil}

Conflict of interest: None declared

\section{INTRODUCTION}

Dental implant is an artificial tooth root fixed into the jaws to hold a replacement tooth or bridge. These are an ideal

\footnotetext{
${ }^{1}$ Professor and Head, ${ }^{2}$ Postgraduate Student, ${ }^{3}$ Assistant Professor

${ }^{1-3}$ Department of Prosthodontics, Government Dental College and Hospital, Ahmedabad, Gujarat, India
}

Corresponding Author: Anandmayee Chaturvedi, Postgraduate Student, Department of Prosthodontics, Government Dental College and Hospital, Ahmedabad, Gujarat, India, Phone: 9824539197, e-mail: dranandmayee@gmail.com option for people in good general oral health who have lost a tooth or teeth. These are also used for the treatment of edentulous patients and are associated with improved denture retention, stability, functional efficiency, and thus improving the quality of life..$^{1-3}$ Around one million dental implants are inserted each year, worldwide. ${ }^{4}$ However, the information which is available to the patients regarding the procedure and its success, is often fragmentary. This problem is more compounded in developing nations.

Level of awareness about dental implant treatment varied among several studies in different countries. Reports from Finland ${ }^{5}$ found low levels of awareness among patients about dental implant treatment procedures. A survey report from Austria ${ }^{6}$ reported that the awareness rate of dental implant procedure was 72 and $42 \%$ of those who questioned said that they were not informed at all about dental implants, while only $4 \%$ said they were well informed about dental implants. Source of information plays a key role in improving the level of awareness of dental implants which can be provided by various means. In some countries like United States media played a major role in public dental education when compared to the contribution from dentists. ${ }^{7}$ Berge concluded that mass media like periodicals, TV, and broadcasts are reported to be the main sources of mostly negative information about dental implants ${ }^{8}$ and that the treatment cost, fear of surgery, and long postsurgical period may prevent people from undergoing dental implant treatment.

As India is still considered as a developing country, with people having low levels of literacy and awareness regarding dental implants and their uses, there is paucity of information regarding the awareness of patients about dental implants in this country. Considering this, a study was conducted with an aim to assess the sources, level of awareness, and need for information about dental implants among patients attending the outpatient ward of department of Prosthodontics, Government Dental College and Hospital, Ahmedabad, India.

\section{MATERIALS AND METHODS}

This Questionnaire based survey was conducted during April 2014 for a period of 1 month. All patients attending the outpatient department of Prosthodontics in Government Dental College and Hospital, Ahmedabad were included. 


\section{Ethical Permission}

Before onset of the survey, an ethical permission was taken from the ethical committee of the Institute and a written informed consent was obtained from all the participants.

\section{Data Source}

A pilot survey was done among 20 subjects and a sample of 300 patients was finalized. They were grouped according to :

A. Sex ........... Male, Female

B. Age ........... 16 to 30 years, 31 to 45 years, 46 to 60 years, and above

C. Education levels ........... Up to Secondary education (up to 12th), above secondary education (Graduation, Postgraduation).

\section{Inclusion and Exclusion Criteria}

All the subjects coming to dental college and who were willing to give informed consent and above 16 years of age were included.

\section{Questionnaire}

The data was collected in the form of a questionnaire which was similar to the one which was used by previous researchers. ${ }^{8}$ Patients were asked questions like have they heard about implant, from where they get to know about implant, do they know about the procedure, do they find it affordable and are they willing to go for implant as a treatment of missing teeth ?Those patients who had not heard of dental implants as a treatment option were educated in this regards and were then further questioned.

\section{Data Analysis}

For data analysis, each positive response was given a score ' 1 ' and each negative response was assigned as a score of ' 0 '. Individual scores were summed up to yield a total score. The Statistical software namely SPSS version 16.0 was used for the analysis of the data. Fisher's exact test was used to determine significance of data.

\section{RESULT}

Out of the 300 patients who were interviewed, only 124 $(41.33 \%)$ had heard of the implant procedure, while the remaining $176(58.67 \%)$ had no knowledge about the implant procedure. The characteristics of those participants who had heard about dental implants, like sex, age and education are mentioned in (Table 1).

\section{SOURCES OF INFORMATION}

Among those who were aware of dental implants, $69.35 \%$ had heard about dental implants from their dentist, while only $20.96 \%$ had heard it from other sources of information like the media. The details of this data are given in (Table 2).

\section{WILLINGNESS TO CONSIDER IMPLANT AS AN TREATMENT OPTION}

The patients who had not heard of dental implants were informed about the procedure and were then further questioned. (Table 3 ) shows the details of the patients who would consider dental implants as a treatment option if needed. After knowing the details of the procedure, $45.33 \%$ of the people were willing to use the dental implants as a treatment and $52.67 \%$ were not willing to use them, while $2 \%$ were not sure about their judgment (see Table 3 ).

Among the 158 patients who did not consider implants as a treatment option, $124(78.48 \%)$ cited high cost as the main reason for the refusal, while $34(21.51 \%)$ stated that it was a surgical procedure and they did not want to go for implants because of fear of surgery.

\section{DISCUSSION}

A survey was conducted among the urban population residing in Ahmedabad, regarding the awareness about implants as a treatment modality. Among the 300 patients that were questioned, only $41 \%$ had heard about the dental implants as a treatment modality, thus indicating the lack of awareness among people regarding dental implants. However, the findings were lower than studies conducted by Zimmer et al (1992), ${ }^{7}$ Berge (2000), ${ }^{8}$ and Tepper et al $(2003)^{6}$ which reported the level of awareness as $77 \%, 70.1$ and $72 \%$, respectively. This might be due to low socioeconomic status and low education level among the study population. Also, majority of the participating patients were unskilled workers and educated only till secondary school level or less.

Here, we found that around $58.67 \%$ of the sample did not have any idea about implants and most of them were willing to know more information about implants, their advantages

Table 1: Characteristics of all participants and those who had heard of dental implants as a treatment option

\begin{tabular}{lclll}
\hline \multicolumn{5}{c}{ Awareness of Dental Implants } \\
\hline Sex & Total & $\begin{array}{l}\text { Percentage } \\
(\%)\end{array}$ & Aware & $\begin{array}{l}\text { Percentage } \\
(\%)\end{array}$ \\
\hline Men & 176 & 58.67 & 84 & 47.73 \\
Women & 124 & 41.33 & 40 & 32.26 \\
Total & 300 & - & 124 & 41.33 \\
Age groups & & & & \\
16-30 & 160 & 53.33 & 84 & 52.50 \\
$31-45$ & 72 & 24.00 & 12 & 16.67 \\
$46-60$ & 68 & 22.67 & 28 & 41.18 \\
$\begin{array}{l}\text { Education } \\
\text { Up to secondary }\end{array}$ & 138 & 46.00 & 12 & 8.70 \\
$\begin{array}{l}\text { Above secondary } \\
\text { (Graduate and PG) }\end{array}$ & 162 & 54.00 & 112 & 69.14 \\
\hline
\end{tabular}


Dental Implants as a Treatment Modality: Awareness Survey among People of Ahmedabad

Table 2: Sources of information about dental implants as a treatment modality

\begin{tabular}{llllllll}
\hline & \multicolumn{9}{c}{ Source of Information } \\
\hline & $\begin{array}{l}\text { Total aware } \\
\text { persons }\end{array}$ & Dentist & \multicolumn{1}{c}{ Magazines/internet } & \multicolumn{2}{c}{$\begin{array}{l}\text { From friends undergone the } \\
\text { same treatment }\end{array}$} \\
\cline { 3 - 8 } & & Number & Percentage (\%) & Number & Percentage (\%) & Number & $\%$ age \\
\hline Men & 84 & 54 & 64.29 & 18 & 21.43 & 12 & 14.29 \\
Women & 40 & 32 & 80.00 & 8 & 20 & 0 & 0 \\
Total aware person (M + F) & 124 & 86 & 69.35 & 26 & 20.96 & 12 & 9.67 \\
\hline
\end{tabular}

Table 3: Willingness to consider dental implants as a treatment option

\begin{tabular}{llll}
\hline \multicolumn{3}{c}{ Willingness for Implant } \\
\hline Willing & Total & Men & Women \\
Not willing & $136(45.33 \%)$ & $80(58.82 \%)$ & $56(41.18 \%)$ \\
Not sure & $6(2 \%)$ & $6(100 \%)$ & 0 \\
\hline
\end{tabular}

and disadvantages. This finding is similar to that reported in an Indian study conducted by Satpathy et al. ${ }^{9}$ Most of the patients were not interested in having removable prosthesis as the treatment in replacing missing teeth, which confirms the fact that most patients prefer fixed prosthesis in replacing their missing teeth regardless of the clinical situation they have. This result was in accordance with those concluded by Tepper et al, Zimmer et al. ${ }^{6,7}$ Regarding the source of information our results were similar to study done by Johany SA et $\mathrm{al}^{10}$ (2010) which also stated that most of the people get aware about implants by the dental professionals. However, studies conducted by Zimmer et $\mathrm{al}^{7}$ (1992), showed that media was found to be the main source of information about dental implants, while the dentists were the source for such information in not more than $17 \%$ of the cases. Similarly Berge $(2000)^{8}$ and Best $(1993)^{11}$ also observed media as the first source followed by dentists. When questions were asked regarding hindrances of implant treatment, most of subjects reported that they do not go for implants because they cannot afford. Others were having fear of the

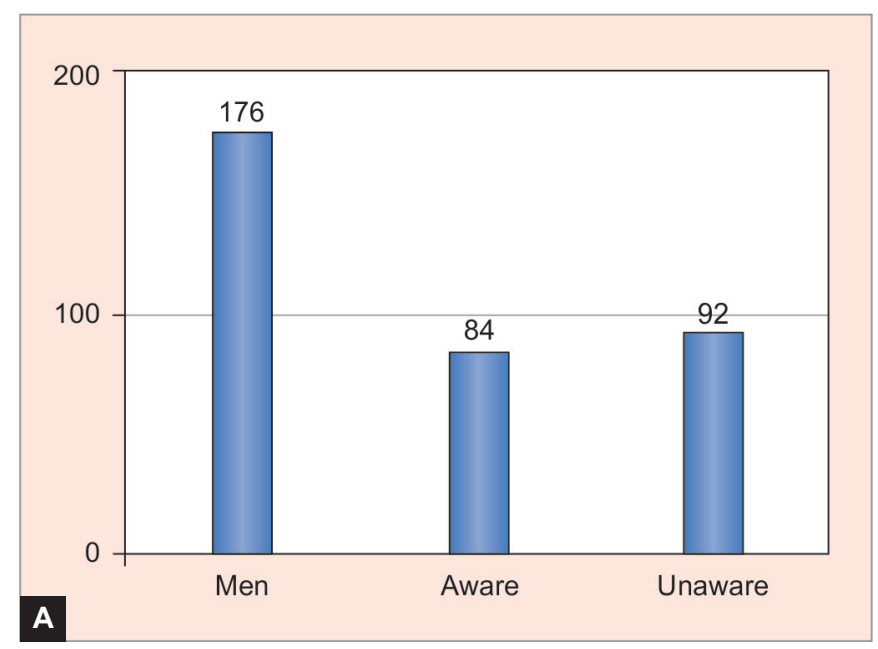

Graphs 1A and B: Awareness of implants according to gender:
Table 4: Test to know if gender plays any role in awareness

\begin{tabular}{llll}
\hline Data analyzed & Aware & Unaware & Total \\
\hline Male & 84 & 92 & 176 \\
Female & 40 & 84 & 124 \\
\hline Total & 124 & 176 & $\mathrm{n}=300$ \\
\hline p-value: & 0.0088 & p-value $<0.05$ & $=$
\end{tabular}

word surgery. Similarly many studies found that high cost is the main constraint as Tepper et al $(2003)^{6}$ Kaurani P et al (2010). ${ }^{12}$ The high costs of the treatment indicated that there was a need for dental insurance to cover this procedure for better option among the patients in developing countries.

Two-sided Fisher's exact test was performed and pvalue was 0.0088 which shows the data is very statistically significant. Men are more aware than women, which may be because of education level (Table 4, Graph 1A and B).

Two-sided Fisher's exact test was performed and p-value was lessthan 0.0001 which shows the relation between awareness and education is extremely statistically significant. People who were graduated or postgraduated were more aware about implants (Table 5 and Graph 2A and B).

When the data was compared according to educational qualification of the people, it was found that all the values raised from illiteracy to graduation level. These findings were similar to study conducted by Hasnain F et al (2009). ${ }^{13}$ In general, males had better knowledge and attitude than females which was in contrast with other studies Polychronopoulou et al, (2005) ${ }^{14}$ and Kawamura et al (2005). ${ }^{15}$

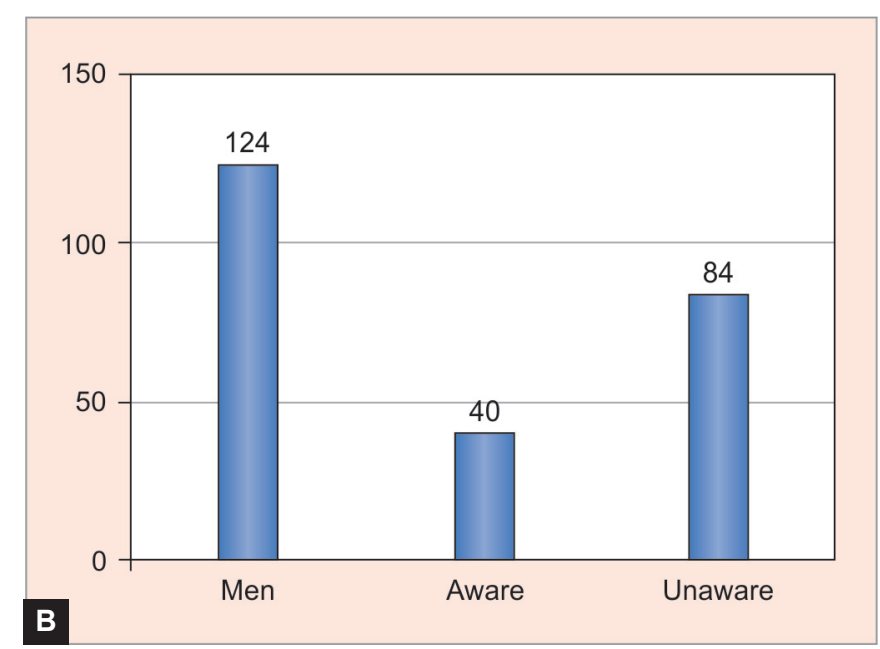

(A) Level of awarness in men, (B) Level of awareness in women 


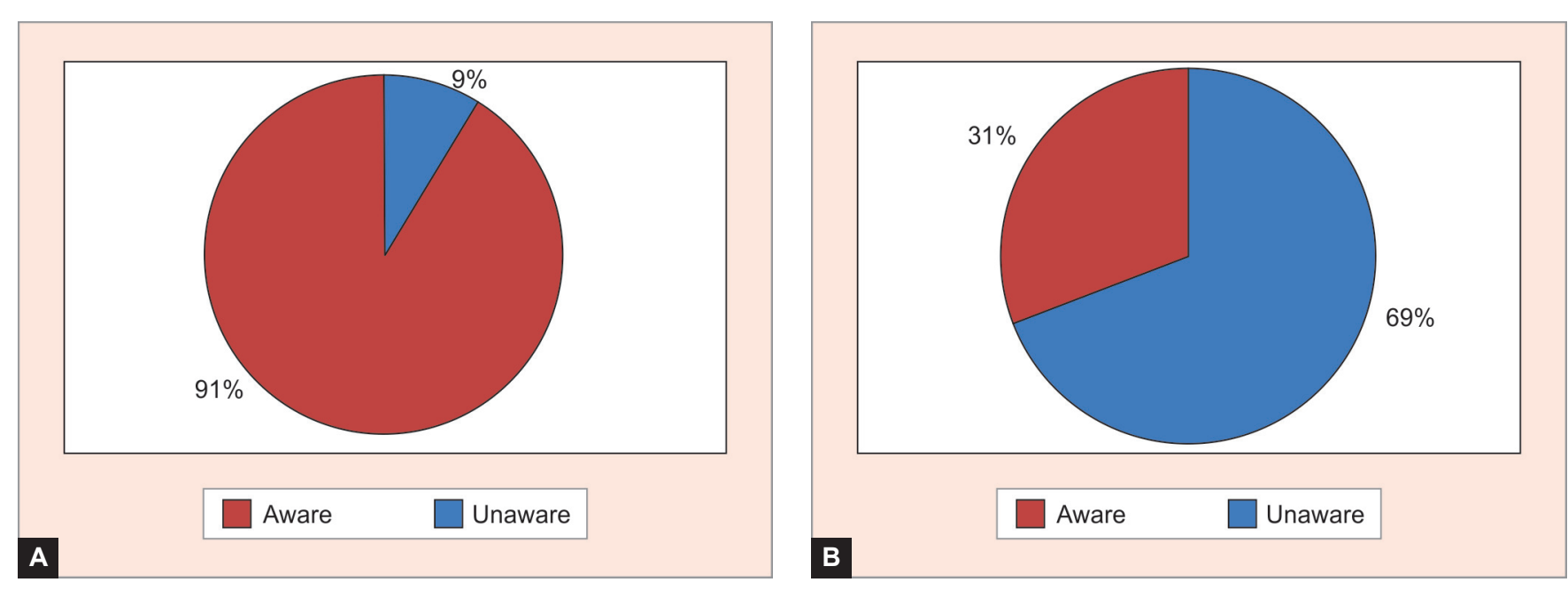

Graph 2A and B: Awareness of implants according to education: (A) Effect of education on awareness (when subjects are educated up to secondary); (B) Effect of education on awareness (when subjects are graduate or above)

Table 5: Test to know if education plays any role in awareness

\begin{tabular}{llll}
\hline Data analyzed & Aware & Unaware & Total \\
\hline $\begin{array}{l}\text { Upto secondary } \\
\text { education }\end{array}$ & 12 & 126 & 138 \\
$\begin{array}{l}\text { Graduate/postgraduate } \\
\text { Total }\end{array}$ & 112 & 50 & 162 \\
\hline
\end{tabular}

p-value $<0.0001$-value $<0.05=$ significant

\section{CONCLUSION}

The results of this survey among a selected sample of dental patients showed that the majority of the questioned subjects were not aware about dental implants, their uses, advantages and disadvantages. They should be informed about implants by conducting and implementing various public awareness campaigns, counseling centers should be established in patient outpatient ward in Prosthodontic departments of dental colleges and in private dental clinics. It also concludes that most of the subjects found implant treatment to be expensive and unaffordable one of the major factor against the willingness of patients to undergo this treatment. But still they were interested to know implants. Thus, various efforts should be made by the public sector to lower the cost of implants so that they can be made affordable to all who are in need and to improve their oral health.

\section{ACKNOWLEDGMENT}

Authors would like to thank Dr Krishn Kant Sharma, BDS, PGDRM, to help them in the statistic calculations.

\section{REFERENCES}

1. Adell R, Lekholm U, Rockler B, Branemark PI. A 15-year study of osseointegrated implants in the treatment of the edentulous jaw. Int J Oral Surg 1981;10(6):387-416.

2. Albrektsson T, Zarb G, Worthington P, Eriksson AR. The longterm efficacy of currently used dental implants: a review and proposed criteria of success. Int J Oral Maxillofac Implants $1986 ; 1(1): 11-25$.
3. Albrektsson T, Blomberg S, Branemark A, Carlsson GE. Edentulousness - an oral handicap. Patient reactions to treatment with jawbone-anchored prostheses. J Oral Rehabil 1987;14(6):503-511.

4. Chowdhary R, Mankani N, Chandrakar N. Awareness of dental implants in urban Indian population. Int J Oral Maxillofac Implants 2010;25(2):305-308.

5. Salonen MA. Assessment of states of dentures and interest in implant-retained prosthetic treatment in 55-year-old edentulous Finns. Community Dent Oral Epidemiol 1994;22(2):130-135.

6. Tepper G, Haas R, Mailath G, Teller C, Zechner W, Watzak $\mathrm{G}$, et al. Representative marketing-oriented study on implants in the Austrian population. I. Level of information, sources of information and need for patient information. Clin Oral Implants Res 2003;14(5):621-633.

7. Zimmer CM, Zimmer WM, Williams J, Liesener J. Public awareness and acceptance of dental implants. Int J Oral Maxillofac Implants 1992;7(2):228-232.

8. Berge TI. Public awareness, information sources and evaluation of oral implant treatment in Norway. Clin Oral Implants Res 2000;11(5):401-408.

9. Satpathy A, Porwal A, Bhattacharya A, Sahu PK. Patient awareness, acceptance and perceived cost of dental implants as a treatment modality for replacement of missing teeth: a survey in Bhubaneshwar and Cuttack. Int J Public Health Dentistry 2011;2(1):1-7.

10. Johany SA, Zoman HA, Juhaini MA. Refeai MA. Dental patients' awareness and knowledge in using dental implants as an option in replacing missing teeth: a survey in Riyadh, Saudi Arabia. Saudi Dent J 2010;22:183-188.

11. Best HA. Awareness and needs of dental implants by patients in New South Wales. Aust Prosthodont J 1993;7:9-12.

12. Kaurani P, Kaurani M. Awareness of dental implants as a treatment modality amongst people residing in jaipur (Rajasthan). $\mathrm{J}$ Clin Diagn Res 2010;4:3622-3626.

13. Hasnain SF, Johansson E, Krantz G. What do young adults know about the HIV/AIDS epidemic? Findings from a population based study in Karachi, Pakistan. BMC Infect Dis 2009;9:38.

14. Polychronopoulou A, Kawamura M. Oral self-care behaviour: comparing Greek and Japanese dental students. Eur J Dent Educ 2005;9(4):164-170.

15. Kawamura M, Yip HK, Hu DY, Komabayashi T. A cross-cultural comparison of dental health attitudes and behaviour among freshman dental students in Japan, Hong- Kong and West China. Int Dent J 2001;51(3):159-163. 